\title{
Social Behavior of Students in Higher Education (Based on the Results of a Sociological Study in the Rostov Region, Russia)
}

\author{
Anatoly Vladimirovich Lubsky ${ }^{*}$, Anastasiya Andreevna Zaytseva \\ Department of Theoretical Sociology and Methodology of Regional Researches, Institute of Sociology and Regional Studies, \\ Southern Federal University, Rostov-on-Don, Russia
}

Received June 15, 2020; Revised August 7, 2020; Accepted August 25, 2020

Cite This Paper in the following Citation Styles

(a): [1] Anatoly Vladimirovich Lubsky, Anastasiya Andreevna Zaytseva, "Social Behavior of Students in Higher Education (Based on the Results of a Sociological Study in the Rostov Region, Russia), "Universal Journal of Educational Research, Vol. 8, No. 10, pp. 4529-4535, 2020. DOI: 10.13189/ujer.2020.081021.

(b): Anatoly Vladimirovich Lubsky, Anastasiya Andreevna Zaytseva (2020). Social Behavior of Students in Higher Education (Based on the Results of a Sociological Study in the Rostov Region, Russia). Universal Journal of Educational Research, 8(10), 4529-4535. DOI: 10.13189/ujer.2020.081021.

Copyright $(2020$ by authors, all rights reserved. Authors agree that this article remains permanently open access under the terms of the Creative Commons Attribution License 4.0 International License

\begin{abstract}
The transformational processes in the field of higher education in Russia, associated with the introduction of new educational practices, actualize the importance of studying changes in the social behavior of university students. The main purpose of the study was to clarify the characteristics of the social behavior of university students, conditioned by external and internal factors. The methodological construct included synthesis of socially deterministic and neoinstitutional approaches, the theory of mental programs, the theory of generations, the value approach of M. Rokeach, as well as the activity-based approach to the study of social practices. Reforms in the higher education system in Russia, which were accompanied by the emergence of a new educational environment and excessive social inequalities, were studied as external factors. Mental programs were studied as internal factors, which included ideas about education as a terminal and instrumental value, attitudes and motives of practices. The research was based on the data of the authors' questionnaire survey of 382 students from 7 universities of the Rostov region. Identifying the features of the mental programs of university students and their educational practices made it possible to identify six types of social behavior of students in the educational sphere: traditional, career, pragmatic, traditional and career, traditional and pragmatic, and career and pragmatic. The analysis of the results allows drawing conclusions about the high
\end{abstract}

readiness of students to new educational practices, which are still poorly implemented. At the same time, motivation depends on mental programs, and the educational practices themselves depend on the conditions created in universities. The results of the study may be of interest to specialists dealing with the issues of social behavior of students in the context of transformations of the higher education system.

Keywords Educational Practices, Mental Programs of Social Behavior, Traditional Social Behavior, Career Type of Social Behavior, Pragmatic Type of Social Behavior

\section{Introduction}

At present, students of higher education institutions present the most active part of Russian youth. Similar to the youth in other developing countries, Russian youth is currently examined not only as a future social resource but also as a social group with the social interests, values, and features of social behavior of its own that can make a significant contribution to the development of society at the present [1-3]. This contribution largely depends on the level of the human capital of higher school graduates which is inextricably linked to their intellectual abilities and social and professional competencies. The formation of 
human capital in students should, therefore, be a priority of Russian higher education institutions.

The formation of human capital in students is affected not only by the current state of the Russian system of higher education but also by their social behavior in the educational sphere. The social behavior of students in higher education is influenced by various internal and external factors. The external factors related to Russian reforms, including the ones in the system of higher education, have led to the formation of the new social and educational environment in Russian society, as well as the emergence of excessive social inequality in it, shaping various educational strategies of students. Along with the social and family environment [4], social networks [5] within which new online identities are formed $[6,7]$ currently have a great influence on the social behavior of students in higher education. The internal factors of student social behavior in higher education primarily include their mental programs composed of students' ideas about education and its role in the realization of their life strategies.

Particular aspects related to studying students' social behavior in the educational sphere in the regional communities in the south of Russia, including the Rostov region, have already been examined in modern sociological literature. In the framework of the social determinism approach, special attention is paid to such external factors of student behavior in the educational sphere as the specific characteristics of the new social and educational environments $[8,9]$. The behaviorist approach $[10,11]$ indicates the financial status of students, the level of their parents' education, and the marital status of the students themselves as the factors of social behavior of students in the educational sphere along with the social environment as a whole [12]. Moreover, researchers accentuate the excessive social inequality of the Russian education system determined by socio-material and socio-territorial factors. The indicated social inequality considers the unequal access to high-quality education, especially for young people from families with low social, cultural, and financial capital [13]. Students' cultural worldview and strategies of social and professional behavior were examined as the internal factors affecting their social behavior including the context of higher education [14].

In studying the social behavior of youth in the educational sphere in the regional communities of the south of Russia researchers paid attention to the fact that, at the turn of the century, the mass consciousness of Russians, including the younger generation, was swept by a conservative wave which determined the antinomic nature of the mental programs of social behavior of youth. This aspect allowed researchers to establish four modal models of social behavior of youth including the educational context - conservative, liberal, conservative-liberal, and liberal-conservative [13]. In scientific research practice, attempts were made to identify the various models of social behavior of students in the sphere of education based on different foundations, such as student culture [15] and successes and risks of socialization in higher education institutions [16].

Thus, the particular aspects related to studying students' social behavior in the educational sphere in regional communities in the south of Russia including the Rostov region have already been examined in modern scientific literature. However, the social behavior of students in the sphere of education in the Rostov region has not yet been an object of sociological research as an integrated social reality. Moreover, previous scientific studies did not identify the specific features of students' mental programs determining their social behavior in education and the specifics of social behavior practices allowing one to differentiate its types were not examined.

This issue involves the formation of a methodological field of research, which can be based on various theoretical approaches and concepts that have been developed within the boundaries of foreign and domestic sociological science. However, in order to achieve the goal set in the article, the following approaches were determined as priority ones: socially deterministic and neoinstitutional approaches [17-19], the theory of mental programs [13, 17, $20,21]$, the theory of generations [22], the value approach of M. Rokeach [23], the activity-based approach to the study of social practices [13].

\section{Materials and Methods}

Studying the social behavior of students in the sphere of education as an integrated social reality calls for the development of a multidimensional methodological construct of multidisciplinary research involving the use of theories and methods of other sciences in the subject field of sociology. This applies primarily to the concept of mental programs suggested by G. Hofstede that presents an effective methodological instrument of cross-cultural research $[20,21]$. The methodological construct of a multidisciplinary study of mental programs of student social behavior in the educational space is based not only on the ideas of G. Hofstede but also on G. Kelly's theory of personal constructs suggesting that people consciously choose from the range of possible options of behavior in a specific social situation the ones that are, in their opinion, the most optimal [17]. In the context of modern neoinstitutional ideas [18], the theory of the personal construct allows identifying the specific characteristics of reflexive structures of students' mental programs including values, attitudes, and motives determining their social behavior in the educational sphere. On the one hand, students can view higher education as an instrumental value presenting the means of achieving certain social goals. On the other hand, it can be perceived as a terminal value in the context of which students view higher education as the goal of their activity. The attitudes of students' mental programs present their readiness for 
conscious social actions in the educational sphere. Motives serve as an inner driving force to encourage students' educational activities. In the framework of modern theories of social practices, the social behavior of students in the sphere of education presents students' response to the current state of higher education in the form of certain educational activities.

Using the methodological potential of the theory of generations [22], we can conclude that the social structure of Russian student community includes millennial students born in the second half of the 1990s in the period of more stable development of Russian society and the centennial students born after the year 2000 who, as indicated by researchers, gained the ability to experiment with their lives with the social institutions created by previous generations being weakened [24].

The empirical basis of the multidisciplinary sociological study of social behavior of students in the field of education in the Rostov region is formed by the authors' questionnaire survey conducted in 7 higher education institutions of the region in December 2019 - January of 2020 in a "face-to-face" format, as well as using the "Surveymonkey" online survey platform [25]. The survey was conducted in Russian. The representativeness of conducted research procedures was ensured via a multistage stratified proportional sampling method (a total sample of 382 respondents).

The questionnaire survey was attended by $230(60 \%)$ girls and $152(40 \%)$ boys, $318(83 \%)$ bachelors and specialists and $64(17 \%)$ masters, $318(83 \%)$ students from stationary universities (SFEDU, DSTU, PSRSPU (NPI), RGEU (RINH), RostGMU) and 64 (17\%) students from university branches (URIU (branch of RANEPA), Novocherkassk Engineering and Melioration Institute named after A.K. Kortunov (branch of DonSAU)), 297 (77\%) students from cities, 85 (23\%) students from rural areas. The questionnaire included two blocks: the social behavior of university students in the educational and civil spheres. The block devoted to the social behavior of students of the Rostov region universities in the educational sphere included questions related to the students' perception of education as a terminal or instrumental value, attitudes as willingness to carry out educational practices of academic mobility and online learning, specific educational practices carried out by students, and also the motives behind these practices. The results of the survey and its sociological analysis and interpretation allowed us to identify the values, attitudes, and motives of students' mental programs determining their social behavior in the sphere of education and the specific features of their educational practices, as well as to indicate the various types of social behavior of students in the sphere of education in the examined region.

\section{Results}

The social behavior of students in the sphere of education is determined by external factors related to reforms in the Russian higher education system. One of the goals of these reforms concerns ensuring the availability of high-quality higher education to students by introducing academic mobility practices in higher education institutions. There are three types of such practices intra-university, intra-Russian, and international. Intra-university mobility practices are implemented within one educational institution and include the form of academic mobility weeks and additional professional education. Intra-Russian mobility practices involve student participation in network educational programs organized by several universities. International mobility practices involve students studying in universities abroad. Regional higher education institutions collaborate with numerous foreign partner universities. For instance, the Southern Federal University collaborates with 217 foreign universities, the Don State Technical University has 109 foreign partner universities, and the Platov South-Russian State Polytechnic University has 53 partnerships. However, in practice such collaborations have an episodic nature allowing a very limited number of students to participate in international mobility practices.

Russian higher education institutions gradually implement various forms of online education. However, this practice is limited to additional education programs. Moreover, the study of students' mental programs demonstrates the low popularity of online learning among them. Most students prefer the familiar forms of contact-classroom education. In this context, we should especially note the very low percentage of students who have successfully completed various online educational courses [26].

The social behavior of students in the sphere of education was also determined by an external factor of the conservative wave that swept over the mass consciousness of Russians at the turn of the century, including the younger generation. This wave had a great influence on the mental programs of students' social behavior in the sphere of education. Only five years ago, the mental programs of students were dominated by the idea of higher education as an instrumental value [13]. At the present, the instrumental value of education as a means of getting an interesting job is significant in the mental programs of $41 \%$ of the students and the terminal value of "high-quality knowledge and skills" in education is found in $38 \%$ of the students. Moreover, higher education is viewed as a terminal value by $43 \%$ of centennial students and $35 \%$ of millennial students. In centennials "high-quality knowledge" is at the first place, and an interesting job rates second, while the opposite is observed in millennials. In this regard, centennial students are more prone to perceiving education as a value in itself. Therefore, for example, they do not pay much attention to education as a means of building a career. It is possible that this also happens because building career strategies currently presents a distant perspective to 
centennials. Senior students become more pragmatic in this regard.

Students' mental programs represent the internal factors of student social behavior in the sphere of education. The results of the sociological study of the specific features of such programs and educational practices allowed distinguishing six types of social behavior of students in higher education: traditional type, career type, pragmatic type, traditional and career type, traditional and pragmatic type, and career and pragmatic type.

The traditional type of social behavior in education that includes about $24 \%$ of students is characterized by a combination of the terminal value of education (acquiring high-quality knowledge) and the instrumental value as a means of acquiring an interesting profession. Students with the traditional type of behavior are characterized by a conservative attitude towards education manifesting in seeking knowledge and preferring the traditional contact-classroom forms of higher education. Therefore, compared to other students, students with this type of social behavior demonstrate higher uncertainty regarding the expediency of transitioning to individual educational trajectories. Concerning the attitude towards online learning, these students perceive it only as a form of higher education complementary to the contact-classroom form.

However, more than $50 \%$ of students with the traditional type of behavior demonstrate readiness for intra-Russian and international mobility. The opportunity to acquire new knowledge and expand the cultural horizons, as well as get acquainted with the organization of education in other Russian and foreign universities serve as their primary motives. However, in practice, such readiness among these students constantly runs up against "the reluctance to skip classes at university" and "leave home for a long time". This presents the manifestation of the conservatism of such mental program structure as attraction to home, family, and social environment. In this regard, students of the traditional type of social behavior are not characterized by a variety of educational practices, since for them its quality is more important than the number. Therefore, students of this type of behavior most often use the possibilities of studying in other scientific fields within their university.

For the students of the career type of social behavior $(20 \%)$ education presents an instrumental value, particularly the means of building a successful career and achieving wealth and high social status. Therefore, they are more prone to participating in international mobility practices since they consider the quality of education abroad to be higher than in Russia. Moreover, the prestige of studying in a foreign university and the possibility of finding a job abroad and staying there is important to them. Students with the career type of social behavior strive to participate in a wide variety of educational programs, since having a greater number of certificates and diplomas is not only prestigious but also useful for building a portfolio which, in the long run, will contribute to their career growth. Concerning the attitude to the possibility of transitioning to an individual educational trajectory, these students prefer not to use this opportunity. They are more comfortable with a common schedule when everything is structured and understandable. These students are more positive about online learning allowing them to avoid wasting time traveling to the university.

To the students of the pragmatic type of social behavior (7\%) education primarily presents an instrumental value (the possibility of "obtaining a diploma", or "deferring draft in the army", "marrying successfully", "extending childhood and postponing the moment of getting a job"). This type of students is characterized by the most positive attitudes towards individual educational trajectories and online learning. Their attitude towards individual educational trajectories is determined by striving to avoid unnecessary disciplines, and the attitude towards online learning is related to the characteristics of online learning that are poorly controlled by teachers and allow the students to spend less time studying [27]. The students of the pragmatic type of social behavior have the lowest readiness for academic mobility: they are not interested in studying in other universities since it will require additional efforts and do not want to leave home and lose the familiar comfort of family. Since to these students, studying in a university presents the means of getting a diploma they do not seek participation in other educational practices.

Within the hybrid traditional and career type of social behavior (36\%) education presents both a terminal and an instrumental value to students. Thus, to them, education simultaneously presents a value in itself related to the desire to acquire high-quality knowledge, the basis for acquiring an interesting profession, and the means of climbing up the career ladder or the social hierarchy. For the students of the hybrid traditional and pragmatic type of social behavior (4\%) education also has not only terminal (high-quality knowledge) but also instrumental value (get a diploma and postpone the moment of getting a job). In the hybrid career and pragmatic type of social behavior (9\%) education presents an instrumental value to students, a means of building a successful career, achieving wealth and higher social status, as well as obtaining a diploma and solving other life problems.

The students of the hybrid types of social behavior in the field of higher education that compose about $50 \%$ of all students demonstrate a more pronounced desire to make a transition to individual educational trajectories compared to the students of the traditional and career types but less so than the students with the pragmatic type of social behavior. However, the presence of various limitations related to the transition to individual educational trajectories present in Russian higher school does not allow one to realize this desire in practice.

The students of the hybrid types of social behavior prefer the classical contact-classroom form of educational process organization. Therefore, they demonstrate lower striving 
for online learning often related to the disappointment in the practice of such learning in universities. The students of hybrid traditional and career and traditional and pragmatic types of social behavior have a high readiness for intra-Russian academic mobility. In general, the students of hybrid types of social behavior in the field of education demonstrate high motivation for international mobility. In the students of the traditional and career type these motives take the form of the desire to know more about education abroad, the prestige of studying abroad, and the high estimation of the quality of such education. The students of the traditional and pragmatic type are motivated by the possibility to travel to other countries and the quality of education abroad and the students of the career and pragmatic type are stimulated by the quality and prestige of education.

Overall, the students of every type of social behavior in the sphere of education are characterized by the readiness, first, to make a transition to individual educational trajectories $(70 \%)$ and, second, to study in other Russian universities $(51 \%)$. Third, over $90 \%$ of the students strive towards studying in foreign universities, the prime motivation for which is the possibility of a more in-depth study of a foreign language. However, the results of the study indicate that this desire of students meets a set of obstacles. Only the students of universities with developed infrastructure and flexible educational programs like the Southern Federal University and the Don State Technical University that present the main universities in the region can afford to participate in intra-Russian mobility practices. Thus, on the one hand, the collaboration of higher education institutions of the region with foreign universities creates favorable conditions for the international academic mobility of students while. On the other hand, student access to participation in international mobility depends on the university they study in.

The main obstacle for students' participation in international mobility is the fact that in most cases, students have to pay for the transferring to another country and living there while studying themselves. Only students from financially secure families can afford this which is also pointed out by foreign researchers [28]. Moreover, while studying in foreign universities; Russian students face several difficulties associated with the mismatch of foreign and Russian credit systems and credit units [29].

\section{Discussion}

The social behavior of students in higher education presenting the repertoire of their educational practices is influenced by a variety of internal and external factors. External factors related to the reforms in the Russian higher education system have led to excessive social inequality and the formation of a new educational environment due to, among other reasons, the introduction of academic mobility practices in universities. The social behavior of students in the sphere of education was also determined by the conservative wave that swept over the mass consciousness of Russians, including the younger generation, at the turn of the century.

This wave had a major influence on the transformation of mental programs including values, attitudes, and motives determining the educational practices and serving as the inner factors of social behavior of students in higher education in this regard. In particular, during the period of liberal transformations in Russian society, in the mental programs of most students, education was viewed as an instrumental value that provided the opportunity for career growth, changes in social status or an increase in material well-being. Education currently presents, first, a terminal value manifesting in the desire to "acquire high-quality knowledge" and, second - an instrumental value considered as a means of acquiring an interesting profession in the mental programs of more than $60 \%$ of students.

In general, the social behavior of students in higher education is characterized by the desire to transit to individual educational trajectories (70\%) and study in other Russian universities (51\%). Moreover, over $90 \%$ of students would like to study in foreign universities primarily with the goal of an in-depth study of a foreign language. However, the practical realization of the desire to transit to individual educational trajectories is only available to an insignificant number of students. Only students of universities with a developed infrastructure and flexible educational programs can count on studying in other Russian universities. On the one hand, the collaboration of higher education institutions with foreign partner universities creates opportunities for students to study abroad. On the other hand, the practical realization of this opportunity depends on the status of a higher education institution the students' study in and their own financial well-being.

Although higher education institutions recently pay increasing attention to online learning practices, this form of education is not popular in the mental programs of students' social behavior. Most students demonstrate the desire to acquire education in the familiar contact-classroom format.

Based on the ideas about education as a value contained in the mental programs of various social groups of students, as well as the characteristics of their educational practices, six types of students' social behavior in higher education can be distinguished: the traditional type including $24 \%$ of students, the career type with $20 \%$ of students, the pragmatic type characteristic of $7 \%$ of students, the traditional and career type including $36 \%$ of students, the traditional and pragmatic type with $4 \%$ of students, and the career and pragmatic type composing $9 \%$ of students.

In the mental program characteristic of the traditional type of student behavior, education presents a terminal 
value emerging in the desire for high-quality knowledge of the one hand and an instrumental value viewed as a means of acquiring an interesting profession on the other. The students of this type seek to acquire high-quality knowledge via the traditional contact-classroom forms of educational process organization. Therefore, they perceive the transition to individual educational trajectories as personally inexpedient and accept online learning only as a supporting form compared to auditory classes. As a result, the students participate in a limited range of educational practices.

In the mental program of students of the career type of social behavior, education presents an instrumental value a means of building a successful career and rapidly progressing in the social hierarchy thus ensuring a higher level of material well-being. These students prefer not to use the opportunity of individual educational trajectories. It is more important to them to simultaneously participate in various educational practices the benefit of which is seen by them in the opportunity to get as many diplomas and certificates as possible. This aspect is primarily significant for them in the context of forming a portfolio that, as they believe, would not only contribute to getting a job but also allow them to take higher positions and promote their career advancement. The desire to master various educational programs determines the positive attitude of these students to online learning that allows them to avoid wasting time on trips to classes.

In the mental program of students with the pragmatic type of social behavior education also presents an instrumental value related to the possibility of getting a diploma, deferment from conscription, successfully marrying, or extending childhood and postponing the moment of getting a job. These students do not have a desire to participate in various educational practices including the ones related to academic mobility. At the same time, they demonstrate greater striving to make a transition to individual educational trajectories and online learning.

Within the traditional and career type of social behavior which is hybrid, education presents both a terminal and an instrumental value simultaneously. Therefore, in the mental programs of students of this type of education are linked to the possibility of getting high-quality knowledge and acquiring an interesting profession. At the same time, the acquisition of higher education is viewed as a means of ascending the career and social ladder. In the mental program of the hybrid traditional and pragmatic type of student social behavior education also presents both a terminal value related to the desire for high-quality knowledge and an instrumental value as a means of getting a diploma and postponing the moment of getting a job. In the mental program of the hybrid career and pragmatic type of behavior education presents an instrumental value to students, i.e. the means of obtaining a prestigious position, building a successful career, achieving high social status, as well as obtaining a diploma and solving other life problems.

The hybrid types of social behavior in higher education compose about $50 \%$ of all students. Their mental programs compose a more pronounced desire to transit to individual education trajectories than those of other students. However, in practice, this desire faces various academic obstacles present in modern higher education institutions. These students demonstrate greater striving to study in foreign universities. Yet the presence of excessive social inequality in the Russian education system impedes the practical realization of this striving. In the mental programs of these students, the preference is also given to traditional forms of educational process organization. Therefore, they do not seek to receive higher education in the format of online education due to, among other reasons, being disappointed in the realization of such practices in universities.

\section{Conclusions}

The main goal of the study, which was to find out the characteristics of the social behavior of university students, caused by external and internal factors, was achieved. According to the results obtained in the course of the study, there are six types of social behavior of students in the educational sphere: traditional, career, pragmatic, traditional and career, traditional and pragmatic, and career and pragmatic. Analysis of the results allows concluding that students are highly prepared for new educational practices, which are still poorly implemented. At the same time, motivation depends on mental programs, and the educational practices themselves depend on the conditions created in universities.

Since the study considered only educational practices related to academic mobility and online learning, in the future it is possible to expand the subject field taking into account other educational practices. In addition, since the study was based on materials from the Rostov region, a comparative perspective with other regions of Russia seems promising. The results of the study may be of interest from the point of view of a new methodological perspective, as well as for sociologists dealing with the issues of social behavior of students in the context of transformations of the higher education system, and for managers who develop educational policy.

\section{Acknowledgments}

The reported study was funded by the RFBR, project number 19-311-90090.

\section{REFERENCES}

[1] A. Furlong, F. Cartmel. Young People and Social Change: 
Individualization and isk in Late Modernity, Open University Press, Buckingham, 1997.

[2] S. Miles. Youth Lifestyles in a Changing World, Open University Press, Buckingham, 2000.

[3] A. V. Lubsky. Civic consciousness in the youth environment of Russia, Germany, and France, Foundation for science and education, Rostov-on-Don, 2020.

[4] L. J. Sax, K. L. Wartman. Studying the impact of parental Involvement on college student development: A Review and agenda for research, Higher Education: Handbook of theory and research, Springer, New York, 2010.

[5] N. Talooki, M. Ataee, M. Gorji, N. Aghaei. The role of regular internet usage on social behavior of students, Indian Journal of Social Psychiatry, Vol. 33, No. 1, 53-56, 2017.

[6] Online Identity: Who, Me? By Steve Olshansky. 10 October 2016, Online available from https://www.internetsociety.or $\mathrm{g} /$ resources/doc/2016/online-identity-who-me/

[7] Verification of Student Identity in Online Learning Policy. 2020, Online available from https://www.strose.edu/campus -offices/its/about-its/policies/verification-of-student-identit y-in-online-learning/

[8] E. Iu. Kolesnikova, L. Sh. Krupenikova. Regional education system in the South of Russia: trends and problems, South of Russia: the Institute and the strategy of modernization of the economy, High school book, Moscow, 2014.

[9] V. V. Volchik. V. V. Kot, I. M. Shiriaev. Institutes and organizations of higher education (on the example of the Rostov region), Journal of Economic Regulation, Vol. 4, 6-27, 2015.

[10] R. Arifin, M. Binti, N. B. A. Wahab, K. S. Teh, M. Bin, M. S. Otman. Influence of Social Environment on Student's Behaviour, International Journal of Academic Research in Business and Social Sciences, Vol. 8, No. 7, 930-939, 2018.

[11] G. Panisoara, N. Dutaa, I. Panisoara. The influence of reasons approving on student motivation for learning Procedia, Social and Behavioral Sciences, Vol. 197, 1215-1222, 2015.

[12] O. S. Mosienko, V. I. Filonenko, A. S. Magranov, A. V. Ponedelkov. Specific features and contradictions of professional socialization in modern student youth: the results of an interregional sociological study, Power, Vol. 25, No. 5, 18-28, 2017.

[13] A. V. Lubsky. Mental programs and modal models of social behavior in the south of Russia, Social and humanitarian knowledge, Moscow, 2017.

[14] Iu. V. Filonenko. Strategies of social and professional behavior of university students (based on the materials of interregional sociological monitoring studies of 2006-2016), Southern Federal University Publishing House, Taganrog,
Rostov-on-Don, 2017.

[15] V. I. Filonenko, L. A. Shtompel, O. M. Shtompel. Representative culture of modern Russian university youth, Sociological review, Vol. 3, 229-230, 2018.

[16] A. Iu. Iaishnikov. Success factors and risks of university socialization: on the example of students of higher educational institutions of Rostov-on-Don and the Rostov region: summary of a Ph.D. dissertation in sociology, Moscow, 2017.

[17] G. A. Kelly. A brief introduction to personal construct theory, Perspectives in personal construct theory, Academic Press, London, 1970.

[18] J. T. Ishiyama, M. Breuning. Neoinstitutionalism. Social Science, Online available from https://www.britannica.com/ topic/neoinstitutionalism/Historical-institutionalism

[19] D. C. North. Institutions, institutional change, and economic performance, Cambridge University Press, New York, 1990.

[20] G. Hofstede, J. G. Hofstede, M. Minkov. Cultures and organizations - software of the mind. Revised and expanded 3rd edition, McGraw-Hill, New York, 2010.

[21] G. Hofstede, R. R. McRae. Returning to the discussion of personality and culture: the relationship between personality traits and cultural axes, Sociological journal, Vol. 4, 9-41, 2010.

[22] N. Howe, W. Strauss. Generations: The History of America's Future, 1584 to 2069, William Morrow \& Company, New York, 1991.

[23] M. Rokeach. The Nature of Human Values, The Free Press, New York, 1973.

[24] V. V. Radaev. Millennials: how does Russian society change, Higher School of Economics Publishing House, Moscow, 2019.

[25] "Surveymonkey" online survey platform, Online available from https://ru.surveymonkey.com/

[26] N. V. Kuznetsov. Online education: key trends and obstacles, E-Management, Vol. 1, 9-25, 2019.

[27] Can online education replace traditional education? Postnauka - online science magazine, Online available from https://postnauka.ru/point -of-view/155079

[28] D. Messer, S. Wolter. Are Student Exchange Programs Worth It? Higher Education, Vol. 54, 647-663, 2007.

[29] A. Atalar. Student Exchange: The First Step Toward International Collaboration, Successful Global Collaborations in Higher Education Institutions, Springer Nature Switzerland AG, 63-71, 2019. 